\title{
BIOMECHANICAL ASSESSMENT OF MOTOR ABILITIES IN MALE HANDBALL PLAYERS DURING THE ANNUAL TRAINING MACROCYCLE
}

\author{
TOMASZ SACEWICZ1A, SŁAWOMIR BODASIŃSKI'1B, MARCIN ŚLIWA1C, PAULINA SZYSZKA ${ }^{1 \mathrm{D}}$, \\ ZENON MAZUR², ADAM CZAPLICKIIA \\ Józef Pitsudski University of Physical Education in Warsaw, Faculty of Physical Education and Sport \\ in Biata Podlaska, Department of Biomechanics and Computer Science ${ }^{a}$, Department of Basketball and \\ Handballb, Department of Football and Volleyballc, Department of Theory and Technology of Sports Trainingd \\ 2University of Technology and Humanities in Radom, Faculty of Mechanical Engineering, \\ Institute of Applied Mechanics and Power Engineering
}

\begin{abstract}
Mailing address: Tomasz Sacewicz, Faculty of Physical Education and Sport, Department of Biomechanics and Computer Science, 2 Akademicka Street, 21-500 Biała Podlaska, tel.: +48 83 3428847, fax: +48 83 3428800, e-mail: tomasz.sacewicz@awf-bp.edu.pl
\end{abstract}

\begin{abstract}
Introduction. The aim of the study was to determine the torque of the knee extensors and flexors of the lead lower limb, the torque of the shoulder extensors and flexors of the dominant upper limb, and the torque generated by the muscles of the kinematic chain going from the trail lower limb to the hand of the dominant limb in male handball players during the annual training macrocycle. Changes in jump height and throwing velocity were also investigated. Material and methods. The study involved 13 handball players from a Polish second-league team. The measurements were performed four times: at the beginning of the preparation period, at the beginning of the season, at the end of the first part of the season, and at the end of the second part of the season. Torque was measured in isokinetic and isometric conditions. Jumping ability was tested using a piezoelectric platform, and throwing velocity was measured with a speed radar gun. Results. The study found statistically significant differences between the relative torque values of the knee extensors $(\mathrm{p}<0.002)$ and flexors $(\mathrm{p}<0.003)$ of the lead leg measured in isokinetic conditions between the first three measurements and the final one. Isokinetic measurement of the torque of the muscles of the kinematic chain going from the trail leg to the hand of the dominant arm decreased in a statistically significant way at the end of the season. As for the results of the measurement of the torque of the shoulder extensors and flexors in static conditions, no statistically significant differences were observed between the four measurements. However, statistically significant differences were noted in jumping ability and throwing velocity in the annual training macrocycle. Conclusions. The results of the study indicate that there is a need to perform regular assessments of players' strength and jumping ability during the competition period. There is a need to modify the training methods used during the preparation period and in the second part of the season as well as to individualise training at the end of the competition period.
\end{abstract}

Key words: handball, torque, throwing velocity, annual macrocycle

\section{Introduction}

Handball (played in teams of 7 players) has been part of the Olympic Games since 1972. Due to the status and popularity of this discipline and its dynamic nature, research involving handball players has been carried out systematically since the 1960s [1]. One of the characteristic elements of this research is torque measurement, which is most often performed in static conditions $[2,3]$, in isokinetic conditions $[4,5,6]$, or using the 1-repetition maximum (1-RM) test [7, 8, 9, 10].

Of practical importance are also tests measuring throwing velocity. This velocity depends, among others, on the type of throw being performed [9, 11], the players' level of achievement [8], and the configuration of the body at the moment when the ball is thrown [12, 13]; moreover, velocity decreases the more accurate the throw is [14]. Since throwing velocity depends on several different factors, it is useful to supplement strength measurement with the assessment of this variable. This need is further evidenced by the typically low or not very high values of the correlation coefficients calculated for the results of various strength measurements and throwing velocity $[4,5,8,10]$.

Another variable which is often used in assessing players' motor abilities is jump height. This variable can be indicative of the players' capacity to perform jump throws, which constitute $75 \%$ of all the throws performed during the match [15] as well as their ability to block the throws made by the opponents during defensive play. The most popular methods of measuring this variable are the counter-movement jump (CMJ) $[3,8,9,16]$ and squat jump (SJ) $[3,6]$.

The results of measurements may be used to verify and modify the training programmes which are being implemented as well as to estimate the risk of injury [17]. Such data have also been drawn on in order to assess players' motor abilities [18, 19]. Performing such assessments, however, requires having information regarding the physical capacities exhibited by the players during the entire macrocycle, which means that the early 
and late phases of the preparation period and the first and second part of the season should be considered. Among all of the authors cited above, only Gorostiaga et al. [9] performed measurements during the annual macrocycle; the measurements were performed four times, and they included anthropometric parameters, biochemical changes in the blood, speed and endurance capacities, jumping ability, strength, power, as well as the velocity of the ball during the performance of three basic throws. The study involved exclusively elite players.

Although examining elite players is important both from a practical and cognitive point of view, the vast majority of handball players do not have such a high level of achievement. In Poland, for example, only two teams play in the Champions League. For this reason, it is useful to analyse the physical capacities of non-elite players, especially that some future champions begin their sports careers participating in less prestigious tournaments. According to our knowledge, such research involving non-elite players has not been carried out so far.

The aim of the current study is thus to perform a biomechanical analysis of selected motor abilities of handball players who play in the second league (third top league in Poland) during the annual macrocycle.

\section{Material and methods}

The study involved players of a second-league team, which was promoted to the first league after the season which was investigated in the current study. All the players were examined by a sports doctor and were qualified for the study. Both the coach and the players were informed about the research procedure and about the possible risks and benefits related to participating in the study. The study was approved by the Senate Research Ethics Committee of the University of Physical Education in Warsaw. The analysis included the results achieved by 13 players (age: $21.7 \pm 3.8$ years; height: $186.9 \pm 5.7 \mathrm{~cm}$; and weight: $89.1 \pm 9.9 \mathrm{~kg})$.

The training cycle was implemented according to the schedule designed by the coach (fig. 1). The measurements were performed at the following four points during the annual training macrocycle: at the beginning of the preparation period - $T_{1}$ (5/Aug/2015), at the beginning of the competition period $-T_{2}(15 / \mathrm{Sep} / 2015)$, at the end of the first part of the season $-T_{3}$ (16/Dec/2015), and at the end of the second part of the season - $T_{4}$ (16/May/2016).

Before undergoing the tests, the subjects performed a standard warm-up lasting 15 minutes. The measurements were carried out on particular testing stations in a random order by the same persons and following an identical procedure. The best results obtained at each of the stations were included in the biomechanical analysis.

Muscle torque was measured in isokinetic conditions using Biodex System Pro 4 (Biodex Medical Systems Inc., USA). Following the coach's suggestion, we measured the net torque of the muscles acting on the knee joint of the lead leg, that is the limb which bears the weight of the body during the throw. A standard measurement procedure was used: the subjects performed 5 repetitions of extension and flexion at an angular velocity of $60^{\circ} / \mathrm{s}[20,21]$.

As for assessing the net torque generated by the muscles of the biomechanical chain going from the trail leg to the hand of the dominant limb, we used an innovative technique consisting in recreating, to the greatest possible extent, the natural movement that is performed during throwing (fig. 2). The measurement was taken with the following settings: dynamometer ori- entation was $70^{\circ}$, dynamometer tilt was $30^{\circ}$, and the handle of the dynamometer attachment was positioned at the height at which the subject would be holding the ball. The test consisted of 5 repetitions of the movement imitating throwing the ball, and it was carried out at an angular velocity of $60^{\circ} / \mathrm{s}$.

The torque of the muscles acting on the shoulder joint was measured in static conditions (fig. 3) on the measuring station LR2-P (JBA Zb. Staniak, Poland). During the test, the subjects performed 3 repetitions of extension and flexion in a sitting position with the upper limb positioned along the body.

Jump height was measured with the force platform 9281CA (Kistler Group, Switzerland), while the maximal velocity of the ball in the penalty throw (7 metres from the goal), cross-over throw (9 metres from the goal), and jump throw (9 metres from

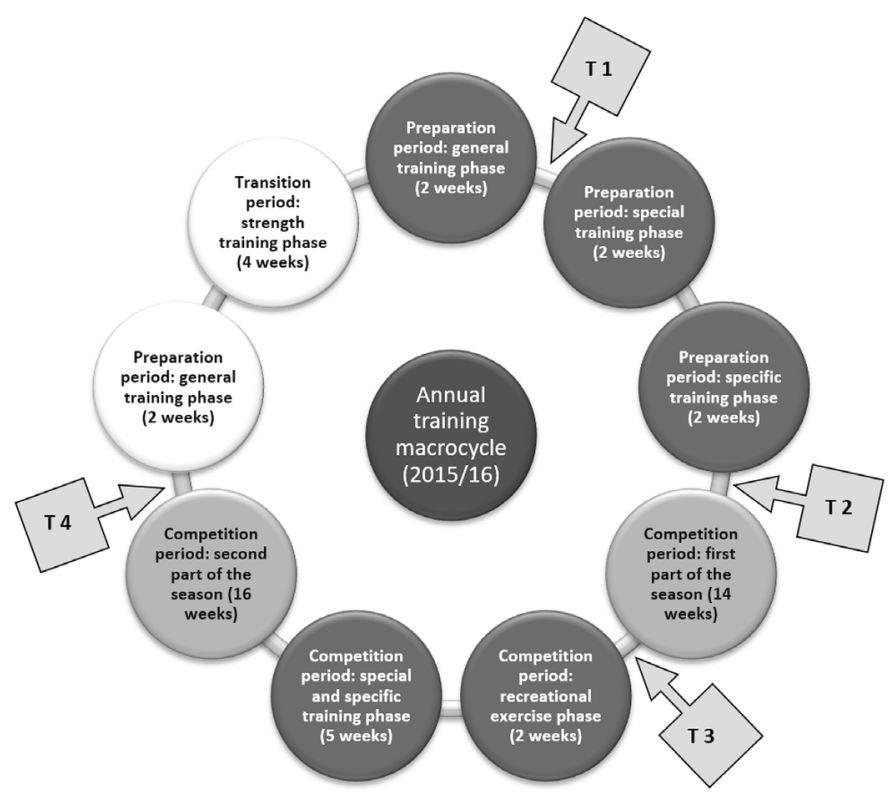

Figure 1. Annual training macrocycle and the measurements performed in the study
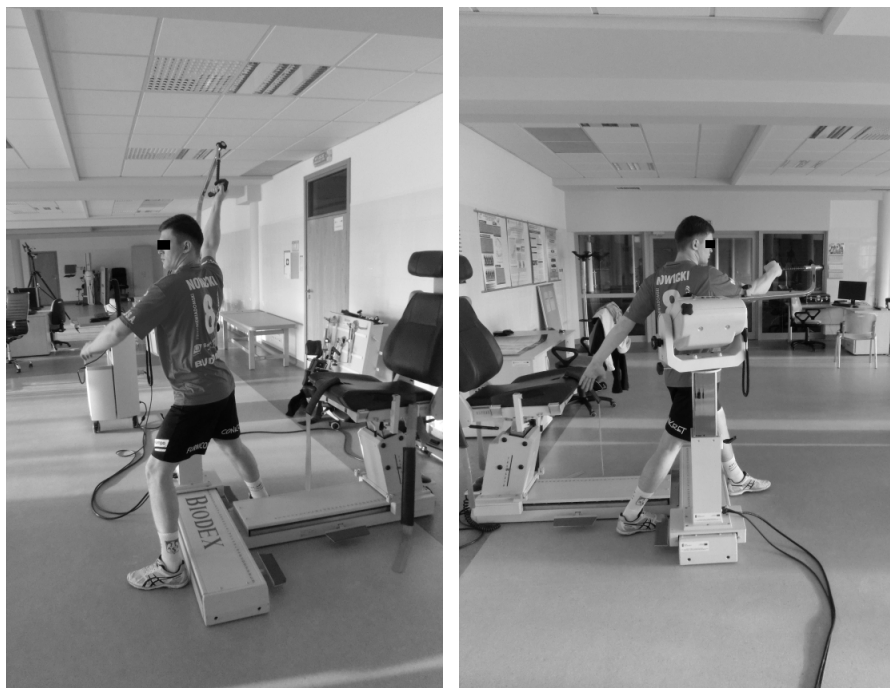

Figure 2. Measurement of the net torque of the muscles of the kinematic chain going from the trail leg to the hand of the dominant limb. Left: start position. Right: end position 


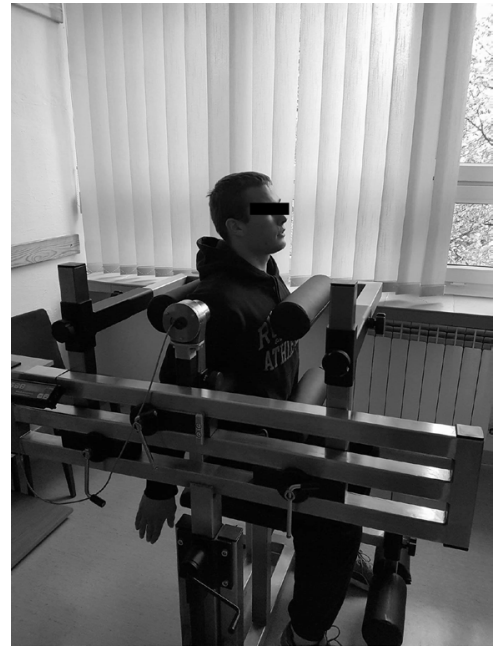

Figure 3. Measurement of the torque of the shoulder muscles in static conditions

the goal) was measured using a speed radar gun (Bushnell, USA). The subjects performed three jumps and three throws using each of the techniques mentioned above.

All the statistical analyses were carried out using Statistica 12 (StatSoft, Poland). First, the data were tested for normality of distribution and homogeneity of variances using the ShapiroWilk test and Bartlett's test. The results, with the level of statistical significance set at $\mathrm{p}=0.05$, confirmed that the data were normally distributed and that the variances were homogeneous. Then, one-way ANOVA with repeated measures was performed; the assumption of sphericity was verified using Mauchly's test. If the results of Mauchly's test were negative, the correctness of the calculations was additionally verified using multi-variate analysis which is not sensitive to violations of the sphericity assumption, taking into account the value of Wilks's $\lambda$. As far as the analysis of throwing velocity is concerned, two-way ANOVA with repeated measures (4 measurements $\mathrm{x} 3$ types of throws) was used. In the final stage of the statistical analysis, we applied the Bonferroni test, which enabled a detailed interpretation of significant differences between the mean values of the variables. We also estimated effect size $\left(\eta^{2}\right)$ which was interpreted as follows: $\eta^{2}>0.01$ - small effect size, $\eta^{2}>0.09$ - medium effect size, and $\eta^{2}>0.25$ - large effect size [22]. In order to create a model which would make it possible to classify the subjects' motor abilities into one of the groups, $T_{\mathrm{i}}(i=1 . . .4)$, we performed an additional discriminant analysis, selecting 7 of the variables examined as independent variables.

\section{Results}

Figure 4 shows the mean relative peak torque of the knee extensors and flexors in the lead leg measured in isokinetic conditions. The torque values recorded in the four measurements, respectively, were as follows: $3.03 \pm 0.29 \mathrm{Nm} / \mathrm{kg}, 3.24 \pm$ $0.41 \mathrm{Nm} / \mathrm{kg}, 3.08 \pm 0.52 \mathrm{Nm} / \mathrm{kg}$, and $2.62 \pm 0.41 \mathrm{Nm} / \mathrm{kg}$ for the extensors and $1.79 \pm 0.31 \mathrm{Nm} / \mathrm{kg}, 1.75 \pm 0.26 \mathrm{Nm} / \mathrm{kg}$, $1.72 \pm 0.42 \mathrm{Nm} / \mathrm{kg}$, and $1.38 \pm 0.27 \mathrm{Nm} / \mathrm{kg}$ for the flexors. Statistically significant differences were found between the results of measurement $T_{4}$ and those of the remaining measurements, both for the extensors $\left(\mathrm{p}<0.002 ; \eta^{2}=0.41\right)$ and the flexors $\left(\mathrm{p}<0.003 ; \eta^{2}=0.39\right)$.

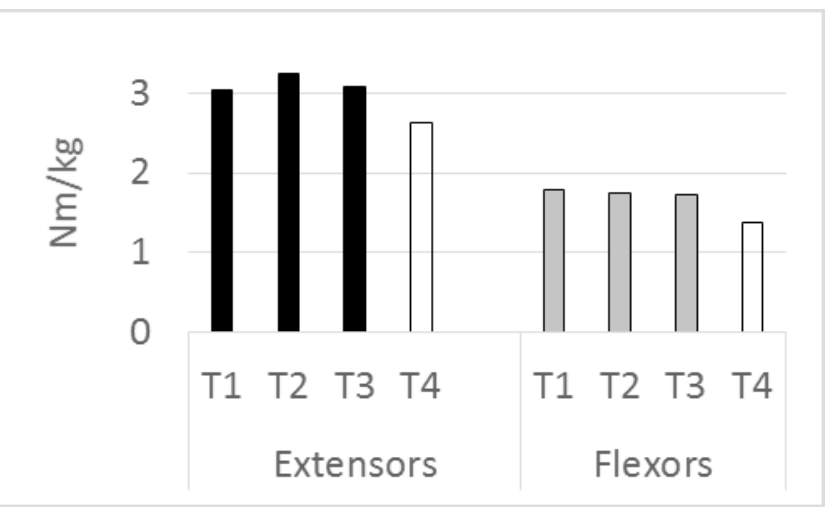

Figure 4. Mean relative peak torque of the knee extensors and flexors of the lead leg measured in isokinetic conditions during the annual training macrocycle. Bars of the same colour are statistically similar

Figure 5 presents the mean relative net peak torque of the muscles of the kinematic chain going from the trail leg to the hand of the dominant limb measured in isokinetic conditions. These values were as follows in measurements 1 to 4 , respectively: $2.03 \pm 0.41 \mathrm{Nm} / \mathrm{kg}, 2.07 \pm 0.38 \mathrm{Nm} / \mathrm{kg}, 1.77 \pm 0.19 \mathrm{Nm} / \mathrm{kg}$, and $1.38 \pm 0.19 \mathrm{Nm} / \mathrm{kg}$. Statistically significant differences $\left(\eta^{2}=\right.$ $0.59)$ were observed between measurements $T_{1}$ and $T_{4}(\mathrm{p} \approx 0.0)$, $T_{2}$ and $T_{4}(\mathrm{p} \approx 0.0)$, as well as $T_{3}$ and $T_{4}(\mathrm{p}<0.024)$.

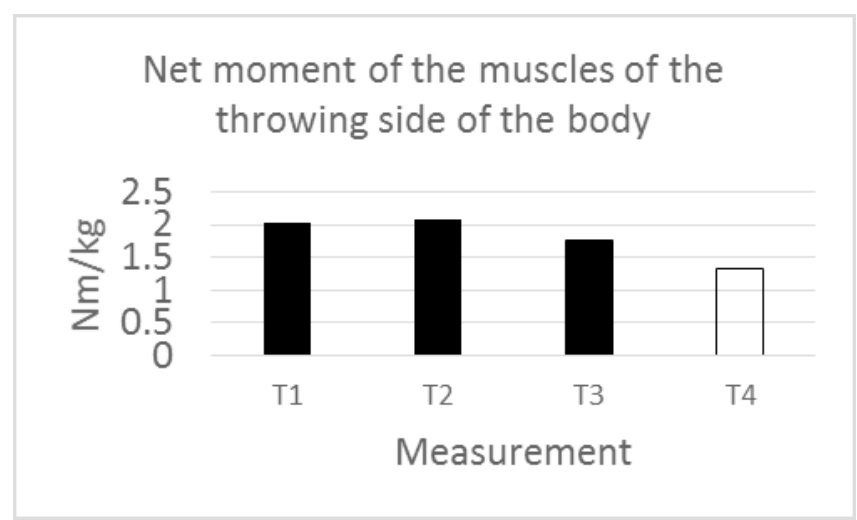

Figure 5. Mean relative net peak torque of the muscles of the kinematic chain going from the trail leg to the hand of the dominant limb measured in isokinetic conditions during the annual training macrocycle. Bars of the same colour are statistically similar

Figure 6 depicts the mean relative peak torque of the shoulder extensors and flexors measured in isometric conditions. The torque values recorded in the consecutive measurements, respectively, were the following: $0.91 \pm 0.11 \mathrm{Nm} / \mathrm{kg}, 0.81 \pm$ $0.10 \mathrm{Nm} / \mathrm{kg}, 0.96 \pm 0.10 \mathrm{Nm} / \mathrm{kg}$, and $0.94 \pm 0.21 \mathrm{Nm} / \mathrm{kg}$ for the extensors and $1.13 \pm 0.21 \mathrm{Nm} / \mathrm{kg}, 1.20 \pm 0.26 \mathrm{Nm} / \mathrm{kg}, 1.19 \pm$ $0.18 \mathrm{Nm} / \mathrm{kg}$, and $1.17 \pm 0.22 \mathrm{Nm} / \mathrm{kg}$ for the flexors. No statistically significant differences were found between these values, neither for the extensors $(\mathrm{p}<0.16)$ nor for the flexors $(\mathrm{p}<0.85)$. 


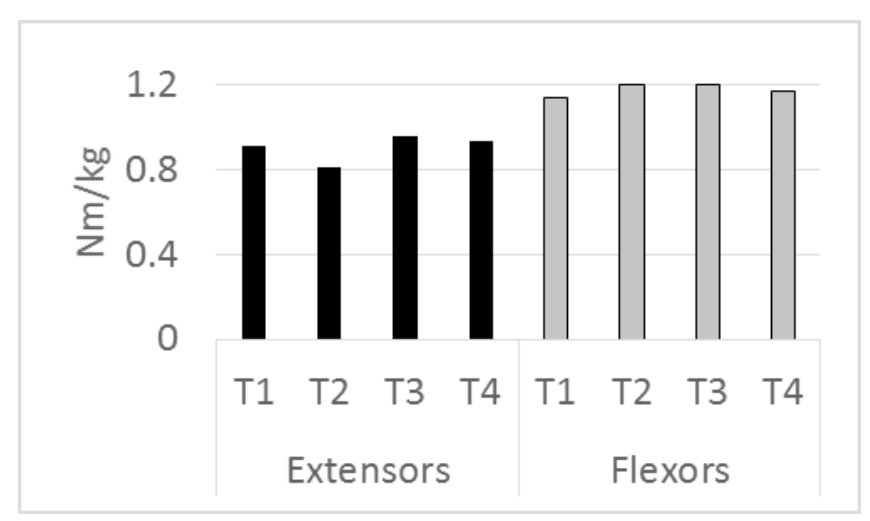

Figure 6. Mean relative peak torque of the shoulder extensors and flexors measured in isometric conditions during the annual training macrocycle. Bars of the same colour are statistically similar

Figure 7 shows the mean jump height values recorded during the performance of the counter-movement jump (CMJ). In measurements 1 to 4 , these values amounted to $0.42 \pm 0.05 \mathrm{~m}$, $0.43 \pm 0.05 \mathrm{~m}, 0.46 \pm 0.06 \mathrm{~m}$, and $0.36 \pm 0.06 \mathrm{~m}$, respectively. Statistically significant differences $\left(\eta^{2}=0.55\right)$ were noted between measurements $T_{1}$ and $T_{4}(\mathrm{p}<0.003), T_{2}$ and $T_{4}(\mathrm{p}<$ $0.001)$, as well as $T_{3}$ and $T_{4}(\mathrm{p} \approx 0.0)$.

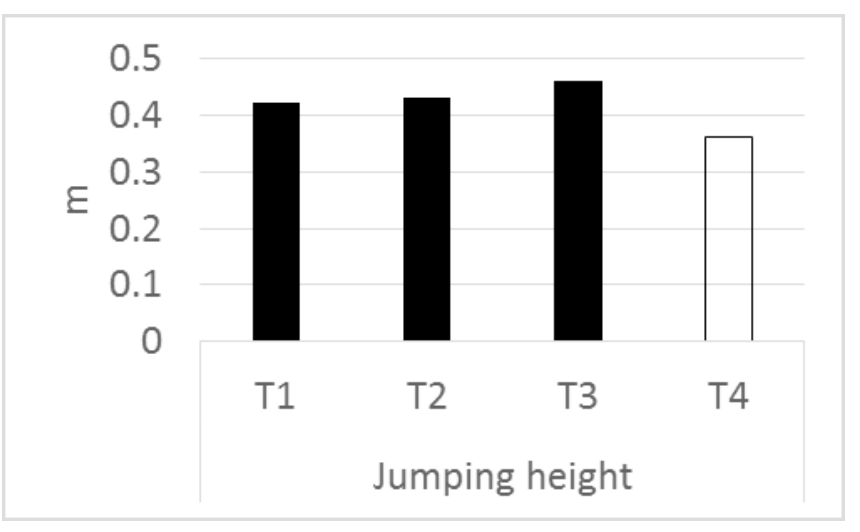

Figure 7. Mean jump height in the CMJ measured during the annual training macrocycle. Bars of the same colour are statistically similar

Figure 8 illustrates the mean throwing velocity recorded during the performance of the three types of throws which were examined. In the penalty throw, the velocity values in the four measurements were $19.19 \pm 2.19 \mathrm{~m} / \mathrm{s}, 19.39 \pm 2.17 \mathrm{~m} / \mathrm{s}, 20.56 \pm$ $1.67 \mathrm{~m} / \mathrm{s}$, and $22.31 \pm 0.89 \mathrm{~m} / \mathrm{s}$, respectively. Statistically significant differences $\left(\eta^{2}=0.64\right)$ were observed between measurements $T_{1}$ and $T_{3}(\mathrm{p}<0.0001), T_{1}$ and $T_{4}(\mathrm{p}<0.0005), T_{2}$ and $T_{3}$ $(\mathrm{p}<0.0008)$, as well as $T_{2}$ and $T_{4}(\mathrm{p}<0.0007)$. Mean velocity values in measurements 1 to 4 in the cross-over throw amounted to $21.40 \pm 1.74 \mathrm{~m} / \mathrm{s}, 21.75 \pm 1.83 \mathrm{~m} / \mathrm{s}, 23.42 \pm 2.57 \mathrm{~m} / \mathrm{s}$, and $22.22 \pm 1.11 \mathrm{~m} / \mathrm{s}$, while those in the jump throw were $20.09 \pm$ $1.21 \mathrm{~m} / \mathrm{s}, 20.56 \pm 1.63 \mathrm{~m} / \mathrm{s}, 22.22 \pm 1.01 \mathrm{~m} / \mathrm{s}$, and $21.19 \pm 0.71 \mathrm{~m} / \mathrm{s}$, respectively. No statistically significant differences were observed between the velocity values in any of the three throws in different periods of the macrocycle. However, we found statistically significant differences $\left(\eta^{2}=0.36\right)$ between the mean velocity values in all the penalty and cross-over throws $(\mathrm{p}<0.009)$ as well as the jump and cross-over throws $(\mathrm{p}<0.01)$ recorded in

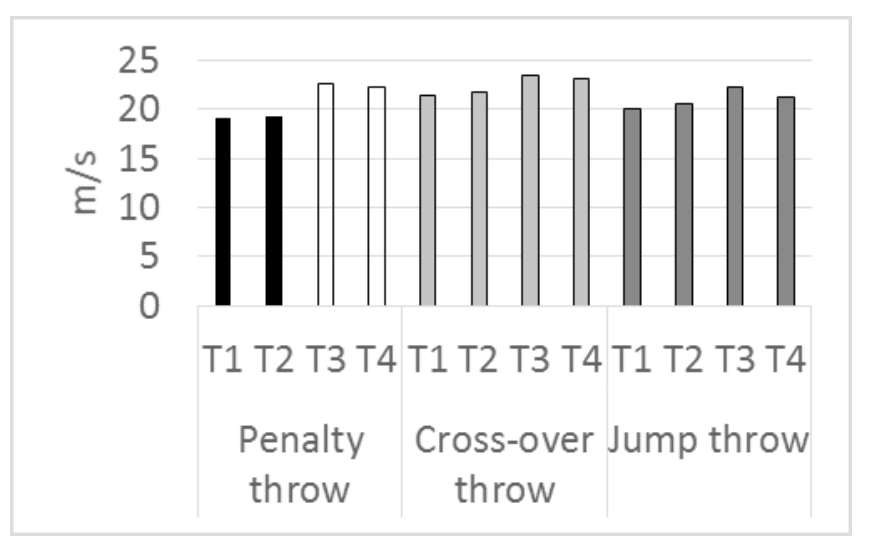

Figure 8. Mean throwing velocity measured during the annual training macrocycle. Bars of the same colour are statistically similar

the entire macrocycle, in addition to a statistically insignificant interaction effect (time $\mathrm{x}$ throw).

The following independent variables were used in the discriminant analysis: the torque of the knee extensors of the lead leg $\left(T_{\mathrm{e}}\right)$, the net torque generated by the muscles acting on the kinematic chain going from the trail leg to the hand of the dominant limb $\left(T_{1}\right)$, the torque of the shoulder flexors measured in isometric conditions $\left(T_{\mathrm{f}}\right)$, jump height $(H)$, as well as throwing velocity in the penalty throw from 7 metres $\left(P_{\mathrm{t}}\right)$, cross-over throw $\left(C_{t}\right)$, and jump throw $\left(J_{t}\right)$. In order to facilitate the interpretation of the results, the analysis was limited to two discriminant functions by assigning the levels $T_{2}, T_{3}$, and $T_{4}$ to the grouping variable. The discriminant function analysis was performed using a stepwise approach. The variables $T_{\mathrm{f}}$ and $J_{\mathrm{t}}$ were not included in the final model. The analysis was found to be statistically significant (Wilks's $\lambda=0.091, p \approx 0.0$ ). The first function $(p \approx 0.0)$ and second function $(p<0.034)$ were also statistically significant. The classifying functions assigned $87 \%$ of the cases to groups $T_{2}$ and $T_{3}$ and $75 \%$ to group $T_{4}$ correctly. To give an example, the analytical form of the third classifying function $F_{\mathrm{c} 3}$ was:

$$
\begin{aligned}
F_{\mathrm{c} 3}= & -192.09-17.09 T_{e}+34.06 T_{1}+106.10 \mathrm{H}+ \\
& 8.69 T_{\mathrm{p}}+6.23 T_{\mathrm{c}} .
\end{aligned}
$$

\section{Discussion}

The first variable analysed in the current study was the relative peak torque of the knee extensors and flexors of the lead leg during throwing. The torque values recorded for the knee flexors in the first part of the season can be considered satisfying, taking into account the norms available on the website of the manufacturer of the dynamometer [23] and the results presented by González-Ravé et al. [6]. The norm for the extensors of the dominant limb given by the manufacturers is between $2.56 \mathrm{Nm} / \mathrm{kg}$ and $3.43 \mathrm{Nm} / \mathrm{kg}$, whereas in the study quoted above, which involved 12 elite handball players from the Spanish League, extensor torque values amounted to $2.7 \pm 0.47 \mathrm{Nm} / \mathrm{kg}$. González-Ravé et al. carried out their study mid-season, which corresponds with the $T_{3}$ measurement in the current study; the results we recorded in $T_{3}(1.72 \pm 0.42 \mathrm{Nm} / \mathrm{kg})$ are similar to the results published by the authors $(1.72 \pm 0.39 \mathrm{Nm} / \mathrm{kg})$ [6]. The high value of knee muscle torque recorded for our subjects, however, was not maintained until the end of the season. At the end of the competition period, we found a radical decrease in exten- 
sor torque to a value of $2.62 \pm 0.41 \mathrm{Nm} / \mathrm{kg}$, which, based on the norms of the manufacturer [23], should be regarded as low.

The method that was used in the current study to measure the torque generated by the muscles acting on the kinematic chain going from the trail leg to the hand of the dominant limb is new. The idea to use it was inspired by the well-documented fact $[12,13,15,24]$ that throwing velocity depends on the configuration of the body and coordination of the rotating and flexing movements of the anatomical segments involved in throwing the ball with maximum velocity. The start and end position of the subjects during the test (fig. 2) shows that their body configuration was similar to the actual configuration during the game. However, it should be emphasised that the upper limb and the dynamometer attachment formed a closed mechanical chain, which imposed kinematic constraints that restricted the movement [25]. The results indicate a severe decrease in this torque value at the end of the season.

The torque of the shoulder extensors and flexors measured in isometric conditions remained at a similar level during the entire season. Assuming that the l-RM test in the barbell bench press is carried out in conditions similar to static ones, the results of our study correspond with those recorded by Pavlovic et al. [26]. The authors observed the value of the 1-RM test, which was performed four times between the $6^{\text {th }}$ and $18^{\text {th }}$ round of the season, to be stable. On the other hand, Gorostiaga et al. [9] found statistically significant - though small - differences between the first and second (2\%) and first and third (1.9\%) measurements. Despite the fact that torque measurement in static conditions has a long tradition [5, 24, 27], norms that would classify the torque values of the muscles discussed in the current study in handball players are difficult to find in the literature. The results obtained in the current study can thus be treated as referential data.

The jump height recorded in the four measurements was $7.1 \%, 8.1 \%, 4.6 \%$, and $24.2 \%$ lower, respectively, than that achieved by elite handball players [9]. While the differences in first three measurements are acceptable and stem from the different levels of achievement of our players and the group of elite players, the substantial decrease in jump height at the end of the competition period indicates that the training implemented in this phase of the macrocycle needs to be modified. It can be suspected that the sharp and statistically significant decrease in jump height observed in the current study is a direct consequence of a drop in the strength capacities of the knee extensors and flexors, which was confirmed by the results of the tests performed for the lead leg.

The throwing velocities recorded for the penalty throw in the first three measurements were $18.1 \%, 18.5 \%$, and $20.9 \%$ lower, respectively, than those achieved by elite handball players [9]. Both in our study and that carried out by Gorostiaga et al., significant differences were found between the same measurements. Moreover, statistically insignificant differences were found for the three throws examined in the current study and the two throws researched by the authors [9] between the third and fourth measurements. Our findings also indicate that the velocity of the cross-over throw from $9 \mathrm{~m}$ was the highest during the competition period, and it was significantly different from the velocities of the remaining throws. Similar results were obtained by Eliasz [24] in a single measurement, although he does not provide information as to the stage of the macrocycle during which the measurement was performed. He calculated the mean velocities of the three throws analysed in our study as well, and his findings were approximately similar to ours. Since the differences found in the current study are not statistically significant, minor changes in throwing velocity values during the macrocycle in the cross-over throw (an 8.6\% increase at the most) and in the jump throw (5.9\% at the most) can be attributed to intra-seasonal variability [28]. Taking into account the fact that after the period that was investigated the team was promoted to the first league, the stable level of the velocity of these throws should be treated as the effect of adequately planned training.

Considering the relatively low size of the data set (168 cases), the results of the discriminant analysis can be regarded as satisfactory, especially that the model proposed in the current study can be supplemented with the results of measurements performed during future tournaments. The fact that the poorest results were achieved in the fourth measurement indicates a high variability of results towards the end of the competition period and suggests that it is necessary to individualise the training in this period of the macrocycle.

To sum up, the current study examined strength, jumping ability, and throwing velocity during the annual macrocycle in male handball players with an average level of achievement. The results of the study indicate that it is useful to monitor the motor abilities of players during the entire league season. The study can be seen as complementary to the pioneering work of Gorostiaga et al. [9], with respect to the type of population examined and the methods used.

\section{Conclusions}

In light of the results of the study presented in this article, modifications should be introduced in the pre-competition period. We would suggest shortening the 6-week interval between the strength training phase and the competition period.

The decreases in most parameters in the final measurement $\left(T_{4}\right)$ indicate that the training programme needs to be changed so that a high level of the strength of the lower limbs and of jumping ability can be maintained. The low level of these variables limits the motor abilities of the players at the end of the competition period.

The significant decrease in the net torque of the muscles of the kinematic chain going from the trail leg to the hand of the dominant limb at the end of the season shows that it would also be helpful to introduce additional exercises for the muscles which are responsible for bending the trunk and rotating the pelvis internally during throwing.

Individualising training during the second part of the season should ensure that the two recommendations presented above are implemented.

The relative torque values of the knee extensors and flexors of the lead leg measured in isokinetic conditions and those generated in the shoulder extensors and flexors recorded in isometric conditions can be treated as referential data and be regarded as the first step towards designing accurate norms in this respect.

\section{Acknowledgements}

The study was supported by the Polish Ministry of Science and Higher Education under Grant No. 0045/RS3/2015/53 for the years 2015-2018.

The experimental data were obtained and processed in the Laboratory of Biomechanics and Kinesiology in the Regional Centre of Research and Development in Biała Podlaska. The Centre was co-financed under the European Regional Develop- 
ment Fund, Operational Programme Development of Eastern Poland 2007-2013.

\section{Literature}

1. Konzag I., Schäcke C. (1968). To the physical load in the game of team handball. Theory and Practice of the Body Culture 17, 875-882.

2. van den Tillaar R., Ettema G. (2004). Effect of body size and gender in overarm throwing performance. European Journal of Applied Physiology 91, 413-418.

3. Vila H., Manchado C., Rodriguez N., Abraldes J.A., Alcaraz P.E., Ferragut C. (2012). Anthropometric profile, vertical jump and throwing velocity in female elite handball players by playing positions. Journal of Strength $\mathcal{E}$ Conditioning Research 26, 2146-2155.

4. Bayios I.A., Anastasopoulou E.M., Sioudrs D.S., Boudolos K.D. (2001). Relationship between isokinetic strength of the internal and external shoulder rotators and ball velocity in team handball. Journal of Sport Medicine and Physical Fitness 41, 229-235.

5. Fleck S.J., Smith S.L., Craib M.W., Denehan T., Snow R.E., Mitchell M.L. (1992). Upper extremity isokinetic torque and throwing velocity in team handball. Journal of Applied Sport Science Research 6, 120-124.

6. González-Ravé J.M., Juárez D., Rubio-Arias J.A., ClementeSuarez V.J., Martinez-Valencia M.A., Abian-Vicen J. (2014). Isokinetic leg strength and power in elite handball players. Journal of Human Kinetics 41, 227-233.

7. Chelly M.S., Hermassi S., Shephard R.J. (2010). Relationships between power and strength of the upper and lower limb muscles and throwing velocity in male handball players. Journal of Strength $\mathcal{E}$ Conditioning Research 24, 14801487.

8. Gorostiaga E.M., Granados C., Ibáñez J., Izquierdo M. (2005). Differences in physical fitness and throwing velocity among elite and amateur male handball players. International Journal of Sports Medicine 26, 225-232.

9. Gorostiaga E.M., Granados C., Ibáñez J., González-Badillo J.J., Izquierdo M. (2006). Effects of an entire season on physical fitness changes in elite male handball athletes. Medicine E Science in Sports E Exercise 38, 357-366.

10. Marques M.C., van den Tillaar R., Vescovi J.D., GonzálezBadillo J.J. (2007). Relationship between throwing velocity, muscle power, and bar velocity during bench press in elite handball players. International Journal of Sports Physiology and Performance 2, 414-422.

11. Eliasz J., Janiak J., Wit A. (1990). Ball flight velocity during throws in handball. Sport Wyczynowy 9-10, 17-23. [in Polish]

12. van den Tillaar R., Ettema G. (2009). Is there a proximalto-distal sequence in overarm throwing in team handball? International Journal of Sports Medicine 27, 949-955.

13. Wagner H., Pfusterschmied J., von Duvillard S.P., Müller E. (2012). Skill-dependent proximal-to-distal sequence in team handball throwing. International Journal of Sports Medicine 30, 821-29.
14. van den Tillaar R., Ettema G. (2006). A comparison between novices and experts of the velocity-accuracy trade-off in overarm throwing. Perceptual and Motor Skills 103, 503-714.

15. Wagner H., Finkenzeller T., Würth S., von Duvillard S.P. (2014). Individual and team performance in team-handball: A review. Journal of Sports Science and Medicine 13, 808816.

16. Michalsik L.B., Aagaard P., Madsen K. (2015). Physiological capacity and physical testing in male elite team handball. Journal of Sports Medicine and Physical Fitness 55, 415-429.

17. Bencke J., Curtis D., Krogshede C., Jensen L., Bandholm T., Zebis M. (2013). Biomechanical evaluation of the side-cutting manoeuvre associated with ACL injury in young female handball athletes. Knee Surgery, Sports Traumatology, Arthroscopy 21, 1876-1881.

18. Michalsik L.B., Aagaard P., Madsen K. (2013). Locomotion characteristics and match-induced impairments in physical performance in male elite team handball players. International Journal of Sports Medicine 34, 590-599.

19. Póvoas S.C., Seabra A.F., Ascensão A.A., Magalhães J., Soares J.M., Rebelo A.N. (2012). Physical and physiological demands of elite team handball. The Journal of Strength $\mathcal{E}$ Conditioning Research 26, 3365-3375.

20. Czaplicki A., Jarocka M., Walawski J. (2015). Isokinetic identification of knee joint torques before and after anterior cruciate ligament reconstruction. PLOS ONE 10(12), e0144283. DOI: 10.1371/journal.pone.0144283.

21. Śliwa M., Sacewicz T. (2015). Biomechanical assessment of the strength of volleyball athletes in different stages of the training macrocycle. Polish Journal of Sport and Tourism $22(3), 148-157$.

22. Cohen J. (1988). Statistical power analysis for the behavioral sciences. Hillsdale, NJ: Erlbaum.

23. Isokinetic testing and data interpretation: normative database. Biodex Medical Systems, Shirley, USA, http://www. biodex.com/sites/default/files/manual-clinical-resourcesnormative.pdf.

24. Eliasz J. (1995). The relationship between throwing velocity and motor ability parameters of the high-performance handball players. In XIII International Symposium for Biomechanics in Sport: Proceedings (pp. 38-43). Thunder Bay, Ontario, Canada: Lakehead University.

25. Czaplicki A. (2009). Modelling in natural coordinates in biomechanics. Biała Podlaska: ZWWF Biała Podlaska. [in Polish]

26. Pavlović L., Bojic I., Radovanović D., Valdevit Z. (2015). Variations of muscular strength and power in male handball players during an entire season. Facta Universitatis, Physical Education and Sport 13, 11-18.

27. Jaszczuk J., Buczek M., Karpiłowski B., Nosarzewski Z., Wit A., Witkowski M. (1987). Set-up for measuring in static conditions. Biology of Sport 4, 41-55.

28. Serrien B., Clijsen R., Anders S., Goossens M., Baeyens J-P. (2016). Intra-seasonal variability of ball speed and coordination of two team-handball throwing techniques in elite male adolescent players. International Journal of Computer Science in Sport 15, 1-21.

Submitted: October 20, 2016

Accepted: December 5, 2016 